\title{
Education, practical training and professional development for public health practitioners: a scoping review of the literature and insights for sustainable food system capacity-building
}

\author{
Jessica Wegener*, Debbie Fong and Cecilia Rocha \\ School of Nutrition, Ryerson University, 350 Victoria Street, Toronto, Ontario, Canada, M5B 2K3
}

Submitted 25 August 2017: Final revision received 5 November 2017: Accepted 12 December 2017: First published online 13 February 2018

\begin{abstract}
Objective: Noting the upstream positioning of sustainable food systems (SFS) to multiple global crises, the present review described examples of emerging and promising practices to support SFS-oriented education, practical training (PT) and continuing professional development (CPD) among trainees and public health practitioners (PHP). A secondary objective was to compile the evidence into practical considerations for educators, supervising practitioners and professional associations. Design: A scoping review of the literature published between 2007 and 2017 was conducted in May 2017 using four databases: CINAHL, MEDLINE, Scopus and HSSA, along with bibliography hand-searching and expert consultation. Articles were screened for relevance and specificity by independent raters.

Results: Nineteen articles were included for analysis. Two-thirds of the articles related to dietitians and public health nutritionists. Emerging practices included curriculumbased considerations, incorporation of 'sustainability' within professional competencies and self-reflection related to SFS. Descriptions of SFS-related education, PT and CPD practices appeared largely in the literature from developed countries. Articles converged on the need for ecosystems, food systems and sustainability considerations within and across practice to support current and future practitioners.

Conclusions: There is growing interest in SFS but guidance to support educators and preceptors is lacking. Updates to dietary guidelines to reflect issues of sustainability are a timely prompt to examine the education, training and development needs of trainees and PHP. Practical examples of emerging practices can empower PHP to promote SFS in all areas of practice. More research is needed to address identified gaps in the literature and to improve SFS-specific education, PT and CPD.
\end{abstract}

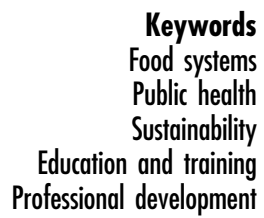

Keywords

ood systems Public health

Professional development
Increasingly, the need to protect the natural environment from harmful human activity is recognized within the field of public health $(\mathrm{PH})^{(1)}$. According to the Ottawa Charter for Health Promotion ${ }^{(2)}$, population health is predicated on a healthy ecosystem and natural resources; environmental concerns are therefore highly relevant to $\mathrm{PH}$ practice. Although the scope of practice within $\mathrm{PH}$ is broad, the actions of $\mathrm{PH}$ practitioners (PHP) converge on their aim to identify and reduce health threats to populations ${ }^{(3)}$. Climate change and natural resource depletion are among the primary environmental threats to populations. The promotion of human and planetary health requires PHP to assess the various factors, including unsustainable human activity, that may be driving environmental threats. The global food system is a growing concern for environmental reasons including, but not limited to, its contribution to deforestation and the decline in other natural resources such as water and soil, intensive agriculture, food waste, carbon emissions and ecosystem pollution ${ }^{(4,5)}$. In addition to food production issues within the global food system, there is a host of other challenges for PHP related to highly processed foods, marketing to children and unhealthy diets and dietary patterns ${ }^{(6-8)}$. PHP are engaged to varying degrees in efforts to ensure a safe and secure food supply that promotes health and food security and reduces the incidence of non-communicable diseases. Despite these concerns, PHP education and training to advance more sustainable food systems and practices is not yet well established ${ }^{(9)}$.

PH researchers are calling for more 'upstream' attention and action within the agriculture and food sectors to 
SFS issues. Additional inclusion criteria included: peerreviewed literature (including dissertations) published in English between 2007 and May 2017. A 10-year time frame was chosen due to the emergence of 'sustainability' and food 'system' considerations within the last decade. Citations were excluded if the focus was related to any of the following unrelated topics: infectious disease, nutrition epidemiology, 'sustainability' in the context of lifestyle choice or the 'sustainability' of a programme or policy intervention ( $v$. 'food system' focus), emergency preparedness training, veterinarian practice and zoonosis.

The initial database search yielded a total of 941 items, as shown in Fig. 2. After two reviewers independently screened titles and abstracts, thirty-five potentially relevant articles were selected for review based on the inclusion and exclusion criteria and after removing duplicates (thirty-five articles) and unrelated literature (871 articles). Sixteen additional pertinent articles were also found through bibliography hand-searching and expert consultation and met the inclusion criteria. In total, fifty-one full-text articles were then screened for their relevance and specificity to the research question by two independent raters. If discrepancies arose in the raters' assessments of relevance or specificity, team deliberation took place until both raters concurred on each of the items in the review. The articles were then grouped into four categories (see Fig. 2). Briefly, Category I (Cat I) articles were considered relevant but lacked specificity. Category II (Cat II) articles met both the relevance and specificity screens (meaning that they were relevant and specific to the research question) and are the primary focus of the review. For the secondary aim of the review, Category III (Cat III) was developed as a category to house 'authoritative knowledge' tools (e.g. professional association position papers) as a support for PHP training, education and CPD (but articles in this category were not specifically related to SFS). Two articles relevant to PHP training and education (not directly related to SFS) were included in a fourth category (Cat IV). These articles did not meet the inclusion criteria but were judged by the authors as offering critical insight into SFS capacity-building within the PHP workforce and were included to support practical recommendations. The results of the review focus on the articles in Category II. Articles were identified as having explicit, tangible, meaningful and content-oriented ideas or action directives for educating, training and developing PHP on the promotion of SFS. Team deliberation was used to discern relevant details about education, training and CPD if these details were less explicit in the articles for the sole purpose of grouping them appropriately (Table 1 discussed below). The purpose of the review was not to compare the quality of articles selected. Rather, the intent
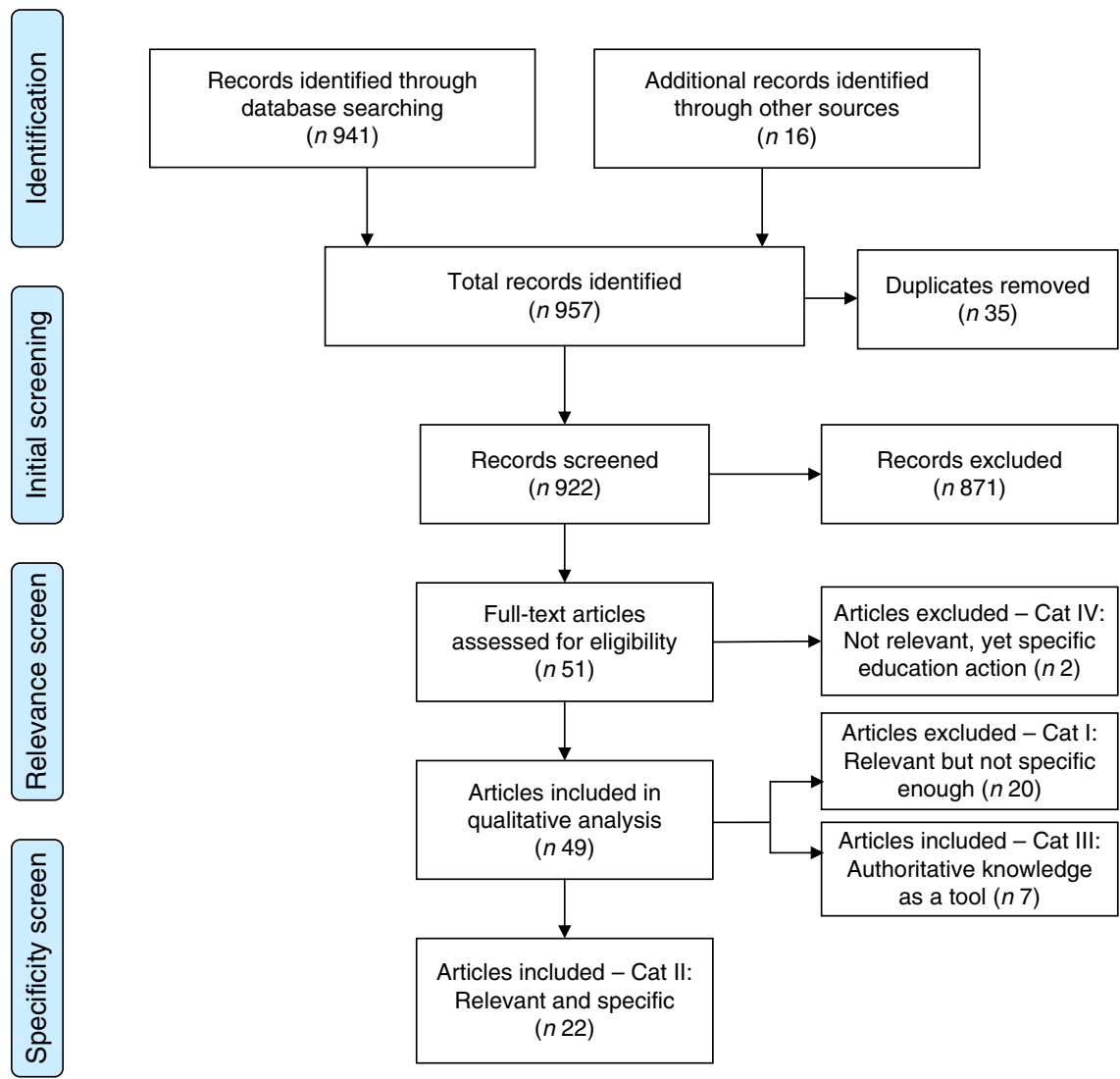

$(n 941)$
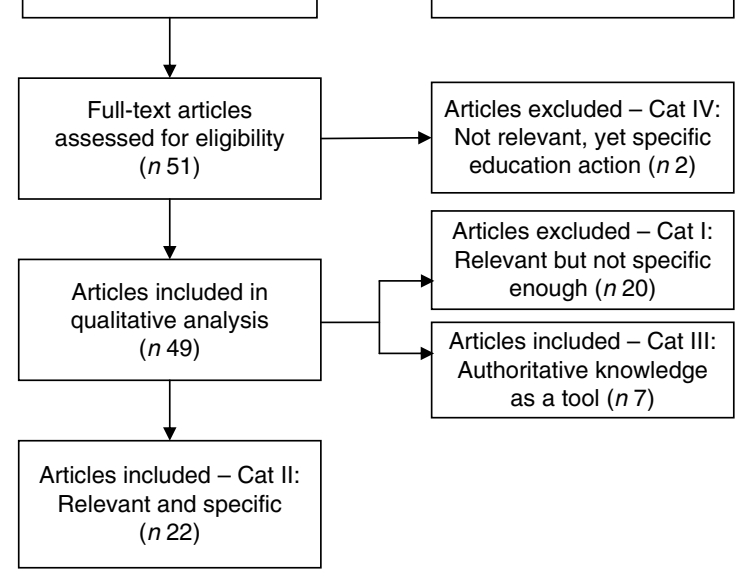

Fig. 2 Flowchart showing search results: English-language citations over the last 10 years to May 2017 included in the present scoping review (Cat I-IV, Category I-IV; see text for explanation) 
was to identify evidence of promising and emerging actions (practices to implement SFS learning in public health) and, therefore, no score or rank was assigned to the selected articles.

\section{Results}

A total of twenty-two articles were included in the review (Cat II). Examples of emerging and promising practices to support education, PT and CPD among students, trainees and PHP in SFS were based on an analysis of nineteen articles (out of twenty-two), as three articles showed substantial content overlap and were written by the same respective lead author(s). Table 1 includes the characteristics of these articles including author, year of publication, country/setting, professional group and area of action (e.g. education, PT, etc.). Overall, the selected items included commentaries ( $n$ 8), case studies ( $n$ 5), surveys $(n 4)$, a practice paper on professional competencies $(n 1)$ and a dissertation ( $n$ 1). Fourteen articles were set in developed countries/nations, including the USA ( $n$ 8), Australia and New Zealand ( $n$ 4), Canada ( $n$ 1) and Europe $(n$ 1). Three articles did not include a particular geographical context, and two were based on North-East Asia (China, Japan, South Korea and Taiwan).

Several articles were less explicit concerning action areas, such as educational levels (undergraduate $v$. graduate), or detail about training focus; and several included content-oriented, actionable ideas directed towards more than one type of PHP group across more than one action area. Overall, two-thirds of the papers (thirteen in total) related to dietitians and public health nutritionists. Three concerned physician training, with two of them also relating to nurses. Other PHP-related professionals discussed in the selected papers included: health promotion practitioners, social workers, veterinarians, food systems workers and students studying nutrition in various disciplines.

Additionally, all articles contained at least one 'working idea' (insight into a promising or emerging practice) to introduce or to enhance existing training and educational activities and approaches related to sustainability or SFS targeted towards students, trainees and PHP. The majority included 'working ideas' at more than one level. Specifically, twelve articles related to education through a university programme at the undergraduate and graduate level(s). Sixteen articles pertained to training and of these, ten referred to specific professional practice competencies or standards of practice. Eleven articles offered actionable ideas to support CPD. Only one ${ }^{(24)}$ of the nineteen articles provided specific recommendations to support PHP educators (those responsible for training or designing education curricula). Key features are examined in the following sections based on identified action areas: (i) university-level education; (ii) PT and competencies; and (iii) CPD.

\section{University-level education}

Concerning university-level education for students and trainees in SFS within a health-related programme, twelve articles made curriculum-based recommendations. Of these, seven provided specific recommendations ${ }^{(18,19,24-28)}$, while others referred to curricular changes ${ }^{(17,20,29-31)}$. Innes et al. ${ }^{(32)}$ and Rojas et $a l^{(33)}$ discussed topic-oriented courses (as opposed to programme curricula) to enhance food sustainability literacy. These curricula and courses spanned a broad range of educational (programmatic) interests and disciplines, including medical and residency programmes ${ }^{(18,27,30)}$, nursing programmes $^{(30)}$, dietetics and nutrition ${ }^{(17,19,20,24,28-32)}$, veterinary programmes ${ }^{(27)}$, food service ${ }^{(25,30)}$, social work $^{(26)}$, health science programmes ${ }^{(19,32)}$ and a food systems programme ${ }^{(33)}$. Several common themes threaded through these proposed curricular modifications. They converged on the inclusion of topics such as: (i) ecosystems; (ii) impacts of climate change on health and sustainability; and (iii) food system sustainability concerns. Other topics related less specifically to SFS but introduced the notion of cross-disciplinary education in curricular design, as highlighted by the One Health framework in Angelos et al. ${ }^{(25)}$ and the humananimal-ecosystem interface in Nabarro and Wannous ${ }^{(27)}$. Environmental and food justice concerns were also identified topics for educational consideration ${ }^{(13,17,26)}$.

\section{Practical training and competencies}

All of the articles related to university-level education, except two ${ }^{(27,30)}$, made reference to PT or professional practice competencies, although some included a more explicit connection between action areas. Specifically, the call to action by Barrett et al. ${ }^{(18)}$ to include climate change health impacts in education curricula also extended to residency programmes which conduct PT. Among the nine articles discussing curricula recommendations for dietetic or nutrition programmes, six of these articles ${ }^{(17,20,24,28,29,32)}$ included a reference to professional competencies and specific knowledge of ecosystem sustainability and food systems in internship training and competencies.

Four articles ${ }^{(15,16,34,35)}$ examined PT or competencies independent of considerations of university-level education. Patrick and Smith ${ }^{(34)}$ and Patrick et al. ${ }^{(15)}$ called for an update of national core competencies for health promotion practitioners in Australia to reinforce and support knowledge about climate change and to include sustainability-promoting practices for climate change adaptation and mitigation. Tagtow et al. detailed the integration of food sustainability in dietetic performance standards, professional competencies and professional development ${ }^{(35)}$. Webber and Sarjahani identified the incorporation of food systems and sustainability concerns into dietetic training, competencies and practice through experiential or service learning ${ }^{(16)}$. Of note, climate change and food systems sustainability were key considerations among articles that discussed professional competencies and PT for PHP. Lastly, several articles included a reference 
Table 1 Characteristics of the Category II articles included in the present scoping review

\begin{tabular}{|c|c|c|c|c|c|c|c|c|c|}
\hline \multirow[b]{2}{*}{ Author } & \multirow[b]{2}{*}{ Country setting } & \multicolumn{5}{|c|}{ Public health profession(s) concerned } & \multicolumn{3}{|c|}{ Specific area(s) of action } \\
\hline & & Doctors & Nurses & $\begin{array}{l}\text { Dietitians/ } \\
\text { nutritionists }\end{array}$ & Others & $\begin{array}{l}\text { Description of } \\
\text { others }\end{array}$ & $\begin{array}{l}\text { University- } \\
\text { based } \\
\text { education }\end{array}$ & $\begin{array}{c}\text { Practical } \\
\text { training } \\
\text { (competency }{ }^{\star} \text { ) }\end{array}$ & $\begin{array}{l}\text { Continuing } \\
\text { professional } \\
\text { development }\end{array}$ \\
\hline $\begin{array}{l}\text { Angelos et al. } \\
\text { (2016) }^{(25)}\end{array}$ & Global & & & & $x$ & $\begin{array}{l}\text { Food systems } \\
\text { workers }\end{array}$ & $\mathrm{x}$ & $x$ & \\
\hline $\begin{array}{l}\text { Barrett et al. } \\
(2015)^{(18)}\end{array}$ & Global/non-specific & $\mathrm{x}$ & $\mathrm{x}$ & $\mathrm{x}$ & $\mathrm{x}$ & $\begin{array}{l}\text { Allied health } \\
\text { professionals }\end{array}$ & $\mathrm{X}$ & $\mathrm{x}$ & $\mathrm{X}$ \\
\hline $\begin{array}{l}\text { Harmon et al. } \\
(2011)^{(24)}\end{array}$ & USA & & & $\mathrm{x}$ & & & $\mathrm{X}$ & $\mathrm{X}^{\star}$ & $\mathrm{X}$ \\
\hline $\begin{array}{l}\text { Innes et al. } \\
(2016)^{(32)}\end{array}$ & New Zealand & & & $\mathrm{x}$ & $\mathrm{x}$ & $\begin{array}{l}\text { Students studying } \\
\text { nutrition from } \\
\text { various faculties }\end{array}$ & $\mathrm{x}$ & $\mathrm{X}^{\star}$ & \\
\hline $\begin{array}{l}\text { Jonsdottir } \\
\text { et al. } \\
(2012)^{(29)}\end{array}$ & Europe & & & $\mathrm{x}$ & & & $x$ & $X^{\star}$ & $x$ \\
\hline $\begin{array}{l}\text { Kaiser et al. } \\
(2015)^{(26)}\end{array}$ & USA & & & & $\mathrm{X}$ & $\begin{array}{l}\text { Social work } \\
\text { students }\end{array}$ & $\mathrm{X}$ & $\mathrm{X}$ & \\
\hline $\begin{array}{l}\text { Meyer } \\
(2015)^{(19)}\end{array}$ & USA & & & $\mathrm{x}$ & $x$ & $\begin{array}{l}\text { Health science } \\
\text { students; health } \\
\text { professionals }\end{array}$ & $\mathrm{X}$ & $x$ & $\mathrm{X}$ \\
\hline $\begin{array}{l}\text { Nabarro and } \\
\text { Wannous } \\
(2014)^{(27)}\end{array}$ & Global & $x$ & & & $x$ & $\begin{array}{l}\text { Veterinary } \\
\text { students }\end{array}$ & $x$ & & \\
\hline $\begin{array}{l}\text { Patrick and } \\
\text { Smith } \\
(2011)^{(34)}\end{array}$ & Australia & & & & $x$ & $\begin{array}{l}\text { Health promotion } \\
\text { practitioners }\end{array}$ & & $X^{\star}$ & \\
\hline $\begin{array}{l}\text { Patrick et al. } \\
(2011)^{(15)}\end{array}$ & Australia & & & & $\mathrm{X}$ & $\begin{array}{l}\text { Health promotion } \\
\text { practitioners }\end{array}$ & & $\mathrm{X}^{\star}$ & \\
\hline $\begin{array}{l}\text { Penland } \\
(2014)^{(20)}\end{array}$ & USA & & & $\mathrm{x}$ & & & $\mathrm{X}$ & $\mathrm{X}^{\star}$ & $x$ \\
\hline $\begin{array}{l}\text { Rojas et al. } \\
(2011)^{(33)}\end{array}$ & Canada & & & & $x$ & $\begin{array}{l}\text { Students studying } \\
\text { food systems }\end{array}$ & $x$ & $x$ & \\
\hline $\begin{array}{l}\text { Tagtow et al. } \\
(2014)^{(35)}\end{array}$ & USA & & & $\mathrm{X}$ & & & & $\mathrm{X}^{*}$ & $\mathrm{X}$ \\
\hline $\begin{array}{l}\text { Vogliano et al. } \\
\qquad(2015)^{(36)}\end{array}$ & USA & & & $\mathrm{X}$ & & & & & $\mathrm{X}$ \\
\hline $\begin{array}{l}\text { Wahlqvist } \\
\qquad(2016)^{(30)}\end{array}$ & $\begin{array}{l}\text { North-East Asia } \\
\text { (China, Japan, } \\
\text { S. Korea, Taiwan) }\end{array}$ & $x$ & $x$ & $\mathrm{x}$ & $x$ & $\begin{array}{l}\text { Food service } \\
\text { students }\end{array}$ & $\mathrm{X}$ & & \\
\hline $\begin{array}{l}\text { Wahlqvist } \\
\text { et al. } \\
(2008)^{(28)}\end{array}$ & $\begin{array}{l}\text { North-East Asia } \\
\text { (China, Japan, } \\
\text { S. Korea, Taiwan) }\end{array}$ & & & $x$ & & & $x$ & $\mathrm{X}^{\star}$ & \\
\hline $\begin{array}{l}\text { Webber and } \\
\text { Sarjahani } \\
(2011)^{(16)}\end{array}$ & USA & & & $x$ & & & & $\mathrm{X}^{\star}$ & \\
\hline $\begin{array}{l}\text { Wilkins et al. } \\
(2010)^{(17)}\end{array}$ & USA & & & $x$ & & & $x$ & $X^{*}$ & $x$ \\
\hline $\begin{array}{l}\text { Worsley et al. } \\
(2014)^{(31)}\end{array}$ & Australia & & & $x$ & & & $x$ & $x$ & $x$ \\
\hline
\end{tabular}

The following three Category II articles were excluded from Table 1 because the same authors' highly similar articles were already captured in the same category. (i) 'Civic dietetics: opportunities for integrating civic agriculture concepts into dietetic practice' by Wilkins $(2009)^{(50)}$ not in the table, given much content overlap with 'Beyond eating right' by Wilkins et al. (2010) (17). (ii) 'Health promotion and climate change: exploring the core competencies required for action' by Patrick et al. $(2012)^{(51)}$ not in the table, given content overlap with 'Beyond eating right' by Wilkins et al. $(2010)^{(17)}$. (iii) 'Eat as if you could save the planet and win!' by Meyer and Reguant-Closa $(2017)^{(13)}$ not in the table, given much content overlap with 'Good food, health, and sustainability' by Meyer (2015) ${ }^{(19)}$.

to training tools. Specifically, critical reflection and experiential learning (also known as service learning) were noted as useful practical training tools ${ }^{(16,19,26,33)}$.

\section{Continuing professional development}

Nine articles in the review identified practices to support CPD for PHP. Of these, seven articles related exclusively to dietetic or nutrition professionals, and specifically identified the need to integrate food systems and sustainability considerations in $\mathrm{CPD}^{(17,20,24,29,31,35,36)}$. These aim to enhance dietitians' and nutritionists' knowledge and confidence in practising sustainability and empower meaningful collaboration with other sectors in addressing these global issues. Several working ideas for CPD were also identified. Examples include multisectoral learning ${ }^{(18,36)}$ and self-reflection ${ }^{(19)}$, and are discussed further below.

\section{Discussion}

Nineteen articles were reviewed in depth. Overall, there was a consensus among authors for the integration of ecosystems, food systems and sustainability considerations within education, training and CPD to support current and future practitioners, with five articles noting it as a moral and professional obligation ${ }^{(16,18,19,24,32)}$. The recency of the articles is telling as more than half were published in the last 4 years, suggesting that SFS-related issues are garnering 
more attention within $\mathrm{PH}$ practice. The review also revealed significant gaps in $\mathrm{PH}$ education, PT, competency development and CPD opportunities. Evidence of emerging and promising practices (in some cases, 'working ideas') to support education, PT and CPD among students, trainees and practitioners in SFS within PH was noted in the results. A secondary aim of the review was to compile the evidence into practical considerations for educators, preceptors and professional practice organizations. The 'working ideas' from the selected articles are summarized below.

\section{Considerations for education, practical training and competency development}

Given the complex and multidisciplinary nature of food systems and sustainability issues, curricular design and PT could consider the adoption of new framework models, such as One Health's ecosystem-food-health framework $^{(25)}$, and cross-sectoral and interdisciplinary learning approaches ${ }^{(18,27,36)}$. While interdisciplinary collaboration has been integrated in some $\mathrm{PH}$ education, training and practice $^{(15,37,38)}$, an SFS-aligned focus within education and training could help foster greater understanding among students and trainees of the positive, far-reaching effects and co-benefits of adopting sustainability principles in future practice. According to Wahlqvist, there is a need to identify opportunities for students and trainees to draw synergies between preventive $(\mathrm{PH})$ and treatment (clinical care) approaches through multidisciplinary and interprofessional collaboration across health professions, such as medical, nursing, dietetic and food-related programmes ${ }^{(30)}$. To facilitate this within educational settings, academic programme developers and educators could develop specific courses or areas of concentration within relevant health-related faculties or university divisions, or offer in-class simulations and case studies. Other operational considerations to support integration or SFS in education and training are short-duration courses or modules on relevant SFS topics including environmental literacy $^{(32)}$, week-long intensive courses on food, community health and sustainability with students and resources from varied academic disciplines ${ }^{(19)}$, and service learning opportunities. Service learning, in particular, has been suggested as a powerful way to add value to communities while providing transformative experiences to students and trainees in skill- and confidence-building ${ }^{(13,16,19,26,33)}$.

Penland noted the apparent lack of implementation of SFS concepts in dietetic practice ${ }^{(20)}$, notwithstanding clear sustainability guidelines of the US Academy of Nutrition and Dietetics. It is suggested that a lack of knowledge and personal perspective among educators or preceptors may be a contributing factor. A mandatory training module to encourage reflection and self-assessment of SFS principles and relevance to practice may be a promising practice for dietetic educators and preceptors to better support student and trainee learning. A similar concern for critical examination and paradigmatic shifts in the values of PHP to support new learning and perspectives concerning SFS was identified by Meyer ${ }^{(19)}$. Described as a '3E concept' for sustainability, Meyer's pedagogical approach included self-reflection on issues related to environment, economy and equity. Similarly, Patrick et $a l .{ }^{(15)}$ proposed a mindset shift to incorporate opportunities for critical self-reflection to support students and trainees as aspiring PHP who not only understand the complex multidisciplinary nature of SFS but can also appreciate and genuinely empathize with all stakeholder perspectives. While not an exhaustive list, these practical ideas can be further considered by educators, practicum coordinators, mentors and supervisors of students and trainees as promising approaches to building SFS capacity and removing the barriers between knowledge and action.

Using appropriate media can facilitate uptake and transformation of sustainability knowledge into professional practice. Training programmes that did include sustainability issues took a variety of approaches, including but not limited to committing didactic time to SFS-related topics, lectures, guest speakers, field trips, webinars and 'green' dining experiences ${ }^{(16)}$. Several studies identified the use of online and distance learning to extend the reach of an expansive curriculum ${ }^{(19,24,25,31)}$. Fieldwork and other forms of service learning relating to sustainability, as well as publications produced by professional associations, reputable journals and other credible sources, were identified as valuable tools. CPD modules related to $\mathrm{SFS}^{(20,31)}$, both voluntary and mandatory, and hosting journal clubs ${ }^{(36)}$ can stimulate learning.

Among the articles addressing professional competencies, eight pertained to the dietetic or nutrition profession $^{(16,17,20,24,28,29,32,35)}$ and two concerned health promotion practitioners (HPP) ${ }^{(15,34)}$. Several of these competency-related articles were quite detailed in mapping training elements to competencies ${ }^{(16,17,34,35)}$. For instance, Patrick and Smith advocated that students and interns be trained on partnership-building, communication and grant-writing skills to improve and support crossdisciplinary collaboration ${ }^{(34)}$.

\section{Considerations for continuing professional development}

Several promising practices for consideration related to CPD emerged from the literature. Of practical relevance is peer-to-peer awareness-promoting efforts and the dissemination of innovative ideas through PHP networks, as supported by the idea of 'managing up' by Patrick et $a l .{ }^{(15)}$. Additionally, professional practice associations and professional working groups responsible for competency updates and developments can identify opportunities and encourage members to engage in SFS advocacy-related work, which has been recognized as a powerful CPD tool $^{(18)}$. These experiences can foster cross-disciplinary knowledge, confidence and leadership skills among experienced PHP while promoting $\mathrm{PH}$ through policy ${ }^{(18)}$. 
Vogliano et al. also recommended opportunities for interdisciplinary communication and learning between dietitians and various stakeholders in agriculture, such as dairy groups, as part of $\mathrm{CPD}^{(36)}$. Others have noted, however, that PHP need to be mindful of longstanding industry alliances presenting a source of conflict $^{(7)}$ and posing potential barriers to the promotion of food sustainability ${ }^{(17)}$. Furthermore, ongoing development of self-assessment tools by professional associations can help PHP identify their current knowledge and competence in SFS and assess areas for further development. The US Academy of Nutrition and Dietetics' evidence-based Standards of Professional Performance can be considered one of the utmost 'promising practices' to help registered dietitian nutritionists assess their skill levels regarding sustainable, resilient and healthy food and water systems ${ }^{20,35)}$.

Aside from identifying practical considerations from the literature, several other comments are worth noting generally. These concern: (i) potential co-benefits with other PH-related initiatives; (ii) leadership and capacity among PHP (dietitians, public health nutritionists, physicians and others), including capacity within current and aspiring professionals and also within developed countries that have workforce capacity; and (iii) gaps in professional competencies. Several articles elucidated the potential for co-benefits when combining health and sustainability goals $^{(13,15,17,19,34)}$. As an example, promoting nutritious and sustainable diets could result in multiple benefits including lower incidence of non-communicable diseases, reduced carbon emissions and other mitigated environmental concerns ${ }^{(15)}$. Studies suggest that PHP, especially the dietetic profession, might be motivated to integrate SFS in their practice with heightened awareness that food sustainability would yield concurrent patient health and environmental benefits, evidence of which continues to mount $^{(15,17,31)}$.

Most Category II articles concerned dietetics and public health nutrition practice exclusively. This reflects the importance of nutrition in $\mathrm{PH}$ practice in general and in SFS in particular. Articles in Category IV (recall, these do not have a SFS-related focus, but are relevant to education, PT or CPD) also emphasize the importance of general and specific nutrition training within $\mathrm{PH}$ practice. Fox et al. called for increased training and education in public health nutrition as part of the professional competencies for Canadian PHP $^{(39)}$. Another recent study identified the absence of nutrition education in medical programmes as a concern ${ }^{(40)}$. Integrating SFS considerations in these studies could further support the necessary reforms in professional practice competencies for PHP.

Several articles ${ }^{(25,26,32,33)}$ in the present review identified examples of practitioner groups engaged in SFS-related activities within $\mathrm{PH}$ but which were not identified among the Public Health Agency of Canada's classification of $\mathrm{PHP}^{(3)}$. These 'allied' health professionals offer significant potential to promote SFS and support workforce capacity-building. For example, social work is not considered a PH profession in Canada ${ }^{(3)}$, but the dual professional role of social workers in $\mathrm{PH}$ has been described ${ }^{(41)}$ and the American Public Health Association recognizes the value of social workers in $\mathrm{PH}^{(42)}$. Community-based social workers can play a key role in addressing food-related concerns, including issues affecting food security, sustainability and justice ${ }^{(26)}$.

Lastly, the value of engaged and aspiring student professionals cannot be overlooked in terms of developing workforce capacity to promote SFS. There were approximately equal numbers of articles in the current review focusing on education and PT. Fewer articles, overall, related to $\mathrm{CPD}$. Reasons for this could be that, in the absence of SFS-specific education and training, current PHP 'learn as they go', or that the majority of CPD content is found in the grey literature. Another possible reason might be a preferential focus among educators, employers and researchers to apply limited resources to train and prepare new entrants to $\mathrm{PH}$ practice (aspiring students and trainees). Innes et al. identified a positive impact on students' literacy of environmental sustainability and attitudes towards resource conservation after a short twoweek learning module ${ }^{(32)}$. A focus on education and training among aspiring PHP with the intent to build workforce capacity is an important area for further research investigation, in light of self-reported lack of knowledge and confidence of PHP in integrating sustainability in their practices $^{(15,20,24,31,32)}$. Patrick et al. described the value of CPD in the promotion of SFS, noting that 'where practitioner confidence, knowledge and skill barriers were identified, they were overcome through professional development, multidisciplinary team work, forming new partnerships and engaging "sustainability experts" in program design,(15) (p. 284).

Workforce capacity-building in SFS is not only relevant to concerned groups of practising PHP, but is also important in the context of 'country of practice'. The SFS-training focus of the current review excluded articles related to undernutrition, infectious diseases, emergency preparedness and other topics with the potential for 'sustainability-related' considerations. SFS was defined broadly ${ }^{(23)}$ and in the context of environmental considerations concerning food production, processing, distribution, consumption and waste removal. Based on the selected articles, SFS-related education, training and CPD practices appear to be better supported by developed countries. In developing nations, the PHP workforce may have limited capacity (agency) to pursue 'sustainability concerns' as PH resources may be tied to actions addressing infectious diseases, poverty or famine. Alternatively, it is also possible that SFS considerations are being incorporated into training curricula in developing countries, but that approaches and methods are not being written up for publication as the primary focus of research. The current review did not aim to identify differences 
between developing and developed countries (i.e. no search terms related to 'developed' or 'developing' were used); however, it was found that developing countries tended to discuss sustainability more often in relation to sustainable development goals rather than in relation to SFS. A strong focus on SFS among HPP in Australia was identified $^{(15,34)}$. One reason for this is that the Australian Health Promotion Association has a broad definition of $\mathrm{HPP}^{(43)}$. Mindset shifts among HPP are likely supported through access to an extensive professional network of Australian Health Promotion Association members with varied experiences and perspectives for cross-sectoral learning. The incorporation of sustainability considerations in the Australian dietary guidelines may also contribute to openness and receptiveness to addressing SFS concerns among HPP. Future research is needed to further evaluate these attributes among PHP working in countries that have adopted similar sustainability messages in their national guidelines, including but not limited to Brazil, Germany, Sweden, France and Qatar ${ }^{(13,44-46)}$

Despite a focus on competency (competen*) in the search queries, only five relevant articles addressed food sustainability in the professional competencies of PHP. An additional five articles were found through bibliography hand-searching. This gap in the literature suggests that SFS-specific competencies have received much less attention among $\mathrm{PH}$ researchers and that this terminology may lack a shared understanding and definition among PHP. Specifically, the integration of food sustainability considerations within competencies of PHP appears to be limited in breadth and depth but could be an indication, as noted by Innes et al., of an oversight in proper documentation $^{(32)}$. Further research to examine the grey literature for updates and reforms to professional practice competencies related to SFS could further support training and help build capacity among current and future PHP. Particularly in developing countries a review of the various competency guidelines across health profession councils could be one way to create a shared understanding of SFS across health-related disciplines.

The present review is the first comprehensive one that provides insights into the extent of SFS-related education, training and CPD among PHP. The search was extensive regarding the construction of search terms applied to four major publication databases with a strong $\mathrm{PH}$ focus. It draws educators' attention to emerging and promising recommendations and potential barriers to effective adoption. It also identifies areas that require further research and development.

\section{Conclusion}

An expert panel identified 'transdisciplinary considerations' as one of ten principles to guide the transition to $\mathrm{SFS}^{(47)}$. While the current review was limited to PHP, there is a need to 'co-produce' knowledge with other key stakeholders who hold a unique understanding of food systems ${ }^{(47)}$. PHP have much to contribute to the debate on food systems reform to promote healthier, more sustainable food systems. There are heightened concerns among $\mathrm{PH}$ organizations, and their associated members, that the current food systems are unsustainable $\mathrm{f}^{(5,15,48,49)}$. To date, the uptake and implementation of food sustainability by PHP remain limited due in part to gaps in education, PT and CPD. Coincidentally, Health Canada has released its intention to follow the lead of other nations, such as Brazil, Germany and the Netherlands, to include environmental considerations in the upcoming Canada's Food Guide. This speaks volumes about the significance of SFS-oriented education, PT and CPD for aspiring students and practising professionals in $\mathrm{PH}$, especially considering the upstream positioning of SFS to multiple global crises. Not least, the collection here of practical examples of emerging and promising practices can empower PHP to promote SFS in all areas of practice.

\section{Acknowledgements}

Financial support: This research received no specific grant from any funding agency in the public, commercial or not-for-profit sectors. Conflict of interest: None. Authorship: J.W., D.F. and C.R. are the sole authors of this manuscript. J.W. formulated the research question and designed the study. D.F. conducted the database searches, organized and analysed the findings in partnership with J.W. J.W. and D.F. reviewed the articles and screened for relevance and specificity. J.W. and D.F. wrote the manuscript. C.R. provided feedback, guidance and editorial support. Ethics of buman subject participation: Not applicable to this review.

\section{References}

1. O'Kane G (2012) What is the real cost of our food? Implications for the environment, society and public health nutrition. Public Health Nutr 15, 268-276.

2. Public Health Agency of Canada (2012) Ottawa Charter for Health Promotion: An International Conference on Health Promotion, 1986. http://www.phac-aspc.gc.ca/ph-sp/docs/ charter-chartre/index-eng.php (accessed July 2017).

3. Public Health Agency of Canada (2017) Core Competencies for Public Health in Canada. Release 1.0, 2008. http://www.phacaspc.gc.ca/php-psp/ccph-cesp/pdfs/cc-manual-eng090407.pdf (accessed July 2017).

4. Allen T, Prosperi P, Cogill B et al. (2014) Agricultural biodiversity, social-ecological systems and sustainable diets. Proc Nutr Soc 73, 498-508.

5. Garnett T, Appleby MC, Balmford A et al. (2014) What is a Sustainable Healthy Diet? A Discussion Paper. https://www. fcrn.org.uk/sites/default/files/fcrn_what_is_a_sustainable_ healthy_diet_final.pdf (accessed July 2017).

6. Story M, Hamm MW \& Wallinga D (2009) Research and action priorities for linking public health, food systems, and sustainable agriculture: recommendations from the Airlie Conference. J Hunger Environ Nutr 4, 477-485.

7. Stuckler D \& Nestle M (2012) Big food, food systems, and global health. PLoS Med 9, e1001242. 
8. Wallinga D (2009) Today's food system: how healthy is it? J Hunger Environ Nutr 4, 251-281.

9. Wegener J \& Petitclerc M (2018) Practicum coordinators' perspectives on emerging settings as an opportunity for practical training in food systems. Can J Diet Pract Res (In the Press).

10. Centre for Disease Control Foundation (2017) What is public health? http://www.cdcfoundation.org/content/ what-public-health (accessed July 2017).

11. Fanzo J (2014) Strengthening the engagement of food and health systems to improve nutrition security: synthesis and overview of approaches to address malnutrition. Glob Food Sec 3, 183-192.

12. Hanlon P, Carlisle S, Hannah M et al. (2012) A perspective on the future public health: an integrative and ecological framework. Perspect Public Health 132, 313-319.

13. Meyer N \& Reguant-Closa A (2017) 'Eat as if you could save the planet and win!' Sustainability integration into nutrition for exercise and sport. Nutrients $\mathbf{9}, \mathrm{E} 412$.

14. Lawrence MA, Friel S, Wingrove K et al. (2015) Formulating policy activities to promote healthy and sustainable diets. Public Health Nutr 18, 2333-2340.

15. Patrick R, Capetola T, Townsend M et al. (2011) Incorporating sustainability into community-based healthcare practice. EcoHealth 8, 277-289.

16. Webber CB \& Sarjahani A (2011) Fitting sustainable food systems into dietetic internships - a growing trend. J Hunger Environ Nutr 6, 477-489.

17. Wilkins JL, Lapp J, Tagtow A et al. (2010) Beyond eating right: the emergence of civic dietetics to foster health and sustainability through food system change. J Hunger Environ Nutr 5, 2-12.

18. Barrett B, Charles JW \& Temte JL (2015) Climate change, human health, and epidemiological transition. Prev Med 70, 69-75.

19. Meyer NL (2015) Good food, health, and sustainability: an introduction for health professionals. ACSM Health Fitness J 19, 12-21.

20. Penland A (2014) Influences related to the diffusion of innovations theory on the incorporation of sustainable food systems practices within dietetic responsibilities. Master of Science Thesis, North Illinois University.

21. Orme J \& Dooris M (2010) Integrating health and sustainability: the higher education sector as a timely catalyst. Health Educ Res 25, 425-437.

22. Hughes R \& Margetts BM (2011) Practical Public Health Nutrition, 1st ed. pp. 9-28. Oxford: Wiley-Blackwell.

23. Eakin H, Connors JP, Wharton C et al. (2016) Identifying attributes of food system sustainability: emerging themes and consensus. Agric Hum Values 34, 757-773.

24. Harmon A, Lapp JL, Blair D et al. (2011) Teaching food system sustainability in dietetic programs: need, conceptualization, and practical approaches. J Hunger Environ Nutr 6, 114-124.

25. Angelos J, Arens A, Johnson H et al. (2016) One health in food safety and security education: a curricular framework. Comp Immunol Microbiol Infect Dis 44, 29-33.

26. Kaiser ML, Himmelheber S, Miller S et al. (2015) Cultivators of change: food justice in social work education. Soc Work Educ 34, 544-557.

27. Nabarro D \& Wannous C (2014) The potential contribution of livestock to food and nutrition security: the application of the one health approach in livestock policy and practice. Rev Sci Tech 33, 475-485.

28. Wahlqvist ML, Li D, Sun J et al. (2008) Nutrition leadership training in North-East Asia: an IUNS initiative in conjunction with nutrition societies in the region. Asia Pac J Clin Nutr 17, 672-682.
29. Jonsdottir S, Thorsdottir I, Kugelberg S et al. (2012) Core functions for the public health nutrition workforce in Europe: a consensus study. Public Health Nutr 15, 1999-2004.

30. Wahlqvist ML (2016) The rise of clinical nutrition science in North-East Asia. Asia Pac J Clin Nutr 25, 437-443.

31. Worsley A, Droulez V, Ridley S et al. (2014) Dietitians' interests in primary food production: opportunities for greater involvement in the promotion of environmental sustainability. J Hunger Environ Nutr 9, 64-80.

32. Innes S, Shephard K, Furnari M et al. (2016) Greening the curriculum to foster environmental literacy in tertiary students studying human nutrition. J Hunger Environ Nutr. Published online: 23 December 2016. https://doi.org/ 10.1080/19320248.2016.1255693.

33. Rojas A, Valley W, Mansfield B et al. (2011) Toward food system sustainability through school food system change: Think \& Eat Green@School and the making of a community-university research alliance. Sustainability 3, 763-788.

34. Patrick R \& Smith JA (2011) Core health promotion competencies in Australia: are they compatible with climate change action? Health Promot J Austr 22, Spec No, S29-S33.

35. Tagtow A, Robien K, Bergquist E et al. (2014) Academy of Nutrition and Dietetics: standards of professional performance for registered dietitian nutritionists (competent, proficient, and expert) in sustainable, resilient, and healthy food and water systems. J Acad Nutr Diet 114, 475-488.e24.

36. Vogliano C, Brown K, Miller AM et al. (2015) Plentiful, nutrient-dense food for the world: a guide for registered dietitian nutritionists. J Acad Nutr Diet 115, 2014-2018.

37. Buse CGG (2015) Analyzing an emerging field of public health practice in Ontario, Canada: the case of climate change adaptation. PhD Thesis, University of Toronto.

38. Patrick R, Noy S \& Henderson-Wilson C (2016) Urbanisation, climate change and health equity: how can health promotion contribute? Int J Health Promot Educ $\mathbf{5 4}$, 34-49.

39. Fox A, Chenhall C, Traynor M et al. (2008) Public health nutrition practice in Canada: a situational assessment. Public Health Nutr 11, 773-781.

40. Adams KM, Kohlmeier M, Powell M et al. (2010) Nutrition in Medicine: Nutrition Education for Medical Students and Residents. Los Angeles, CA: SAGE Publications, Inc.

41. Ruth BJ, Sisco S, Wyatt J et al. (2008) Public health and social work: training dual professionals for the contemporary workplace. Public Health Rep 123, Suppl. 2, 71-77.

42. American Public Health Association (2017) Public health social work. http://www.apha.org/apha-communities/ member-sections/public-health-social-work (accessed July 2017).

43. Australian Health Promotion Association (n.d.) Who we are. http://www.healthpromotion.org.au/about-ahpa/who-we-are (accessed July 2017)

44. Monteiro CA, Cannon G, Moubarac J et al. (2015) Dietary guidelines to nourish humanity and the planet in the twenty-first century. A blueprint from Brazil. Public Health Nutr 18, 2311-2312.

45. Seed B (2015) Sustainability in the Qatar national dietary guidelines, among the first to incorporate sustainability principles. Public Health Nutr 18, 2303-2310.

46. Gonzalez Fischer C \& Garnett T (2016) Plates, Pyramids and Planets. Developments in National Healthy and Sustainable Dietary Guidelines: A State of Play Assessment. Rome and Oxford: FAO and Food Climate Research Network, University of Oxford; available at http://www.fao.org/ 3/a-i5640e.pdf (accessed July 2017).

47. International Panel of Experts on Sustainable Food Systems (2010) IPES-Food: 10 principles to guide the transition to 
sustainable food systems. http://www.ipes-food.org/images/ CoreDocs/IPES-Food_10_principles.pdf (accessed July 2017).

48. Crowley RA (2016) Climate change and health: a position paper of the American College of Physicians. Ann Intern Med 164, 608-610.

49. US Dietary Guidelines Advisory Committee (2017) Part D. Chapter 5: Food Sustainability and Safety. In Scientific Report of the 2015 Dietary Guidelines Advisory Committee. http://www.health.gov/dietaryguidelines/2015-scientific-report/ 10-chapter-5/ (accessed July 2017).

50. Wilkins J (2009) Civic dietetics: opportunities for integrating civic agriculture concepts into dietetic practice. Agric Hum Values 26, 57-66.

51. Patrick R, Capetola T, Townsend M et al. (2012) Health promotion and climate change: exploring the core competencies required for action. Health Promot Int 27, 475-485. 